\title{
Assessment of Socio-Cultural Factors Affecting Nigerian Mothers' Weaning Practice
}

\author{
${ }^{1}$ Abdullahi Ibrahim, ${ }^{2}$ Samar El Housiny Abd El Raouf, \\ ${ }^{3}$ Samia Mahmoud Abd El- Mouty, ${ }^{4}$ Mona Emad Eldien Hussien \\ ${ }^{1}$ B.N.sc. Ahmadu Bello University Zaria Nigeria. \\ ${ }^{2}$ Assistant prof. of Community Health Nursing Faculty of Nursing/Mansoura University Egypt. \\ ${ }^{3}$ Lecturer of Community Health Nursing, Faculty of Nursing /Mansoura University, Egypt. \\ ${ }^{4}$ Lecturer of Community Health Nursing, Faculty of Nursing /Mansoura University, Egypt.
}

\begin{abstract}
Complementary feeding is an important determinant of child growth and development. The practice of weaning is declining despite efforts at all levels to improve it; and with globalization there is concern of possible drift in the traditional weaning practices among Nigerian mothers.

Aim: Assess the socio-cultural factors affecting Nigerian mothers' weaning practice.

Subjects and Method: A cross sectional design was conducted on 308 mothers attending at 15 maternal and child health centers in Birnin Kudu Local Government, Nigeria during the researcher visits. Five structured interviews were used to assess sociodemographic and economic characteristics, knowledge, subjective practice, sociocultural factors and attitude of mothers towards weaning practice.

Results: More than three fourths (78.9\%) of the studied mothers had improper category of subjective weaning practice. Less than half (47.1\%) of them denied their children eating egg as part of their taboo practice. There was a statistically significant association between sociocultural factors and mothers' subjective weaning practice.

Conclusion: Mothers' knowledge regarding weaning was poor and subjective practices were improper. Majority of them were not aware of the current recommendations of weaning practice. Additionally, there was a statistically significant association between sociocultural factors and mothers' subjective weaning practice. Recommendations: Provide public health educations campaigns to promote optimal weaning practices, especially in woman within the reproductive age group. Health education program should be conducted to enlighten mothers on the effect of socio cultural factors on breastfeeding and weaning practice.

Key Words: Weaning, Socio-Cultural factors, Knowledge, Practice, Attitude
\end{abstract}

\section{Introduction}

Childhood malnutrition is the major cause of infant mortality which hugely contribute to under five death worldwide. About 178 million children have been suppressed worldwide and Africa has the highest rates. (1). However Undernourishment causes $35 \%$ of disease burden on children under the age of five. In fact, the greatest practices in the areas of breastfeeding and weaning are important degree with the ability to save the lives of 1.5 million children under five every year (2).

Analysts of weaning practices vary between and within countries. Urban and rural differences, age, breast problems, societal barriers, inadequate care from family, knowledge about good lactation, method of delivery, health system practices and community or cultural beliefs have all been found to influence breastfeeding and weaning. Unwillingness of the infant to eat while exerting favorite to beverage rather than eating, allergic reactions and health problems with child including vomiting, abdominal colic and diarrhea may ascend due to wrong feeding practices adopted by mothers (3). However, it was estimated that, there were 10 million annual deaths of under-five year old children. Over one third of under-five mortality is caused by malnourishment related to inadequate complementary feeding during weaning practice. Initiate safe and nutritionally adequate complementary foods at 6 month is vital to achieve optimal growth, development and health of the children (4).

In Nigeria, nearly half of under five children were underdeveloped, with a less than one third increase from 6 months to half of them at two years, this is a exactly a time when weaning is reached its peak. However, the prevalence of malnutrition among children aged 6month to 2 years is $24 \%$; Wasting was $13 \%$ and $17 \%$ among infant from 6month to 2 years and obesity was $9 \%$ (5Moreover, nearly one million children die in Nigeria before they reach the age of five every year and worldwide is about 11 million. In 2006, there was a forecast of nearly 10 million deaths of infant internationally and inadequate food to children directly increased the risk of child hood illness and contributed to infant mortality significantly. Malnourished children are easily predisposed to childhood illness (6). 


\section{Aims of the study}

The aim of the study is to assess the socio- cultural factors affecting Nigerian mothers' weaning practice.

\section{Research questions}

1. How is the Nigerian mothers' knowledge regarding weaning practice?

2. What are the Nigerian mothers' practices related to weaning practice?

3. What is the effect of socio- cultural factors on Nigerian mothers' weaning practice?

3.1 Study design:

\section{Subjects And Method}

A cross-sectional design was utilized.

3.2. Study Setting:

This study was conducted at 15 maternal and child health centers in Birnin Kudu Local Government in Nigeria.

\subsection{Subjects and sampling:}

The subjects of this study were recruited from mothers attending maternal and child health centers during the researcher visits. Proportion allocation was used to select 308 mothers representing the required sample size based on attendance rate at maternal and child health centers in Birnin Kudu Local Government.

\subsection{Data collection}

The duration of data collection approximately was12 weeks from May to July 2016.The researcher introduced himself to the heads of the selected maternal and child health centers and gave them a brief orientation about aim of the study in order to gain their cooperation and the mothers. The researcher visited maternal and child health centers three times/week, Mondays, Wednesdays, and Thursdays from 9:00 a.m. to 12:00 after noon.

\subsection{Tools used in the study:}

Five tools were developed by the researcher after reviewing the related literature.

Tool I: A structured interview to assess socio demographic and economic characteristics of the mothers

This tool was utilized to assess socio demographic and economic characteristics of mothers such as; age, language, occupation, number of children, religion, level of education, and monthly income.

Tool II: A structured interview to assess mothers' knowledge

This tool was used to assess mothers' knowledge regarding weaning practice such as; meaning of weaning, importance, proper time to start weaning, types of food, amount and number of meals per day, methods of cooking food, and food allergy.

Tool III: A structured interview to assess mothers' subjective weaning practice

This tool was developed to assess mothers' subjective weaning practice such as; preparation of meals, and cooking of weaning food.

Tool IV: A structured interview to assess mothers' socio-cultural factors

This tool was utilized to assess socio-cultural factors which effect on weaning practice such as: Social factors affecting weaning practice, Taboos in weaning practice, native weaning food.

Tool V: A structured interview to assess mothers' attitude

This tool would be Lekart like scale concerned with mothers' attitude regarding weaning practice.

\subsection{Pilot study}

A pilot study was conducted on $10 \%$ of the mothers (31 mothers) they were selected randomly from the same setting and excluded from the studied sample to evaluate the clarity, applicability, and reliability of the research tools and estimate the approximate time required for data collection. Accordingly, the necessary modification was done, some questions were added and others were clarified or omitted.

\subsection{Statistical analysis}

SPSS software package (Stand for statistical product and service solutions version 16) was used for data analysis. Descriptive statistics including frequency, distribution, mean, and standard deviation were used to describe different characteristics. Chi-Square test was used to test the significance of results. P-value of less than 0.05 was considered as denoting statistical significance. Reliability of the tool by Cronbach alpha test ( $\mathrm{r}$ alpha) were $=.966$

\subsection{Ethical considerations}

An approval was obtained from Research Ethics Committee of Faculty of Nursing, Mansoura University. The mothers' verbal approval was obtained. The researcher introduces himself and a simple 
explanation about the aim of the study was given to them. They were assured that their participation in the study was voluntary and that collected data will be treated confidentially and would be only used for the purpose of the study. Participants were informed that they have the right to withdraw at any time from the study without giving any reason.

\section{Results}

Table (1): Sows that the age of the studied mothers ranges from 18 up to 35 with a mean age of (18.98 1.96), majority (89.3\%) of them lie in age category from 18 to less than 27 years. Almost two thirds (64.9\%) of the studied mothers were Hausas. Half $(50.0 \%)$ of the studied mothers had secondary education. Less than two thirds $(63.3 \%)$ of the studied mothers were full house wife. Less than half $(44.8 \%)$ earn less than ten thousand naira monthly. Majority $(80.5 \%)$ of studied mothers belongs to extended.

Table (2): Reveals that, 192 (62.3\%) of the studied mothers had poor knowledge score level about weaning while $87(28.2 \%)$ had good knowledge score level about weaning.

Table (3): Sows that $243(78.9 \%)$ of the studied mothers had improper category of subjective weaning practice while $65(21.1 \%)$ had proper category of subjective weaning practice.

Table (4): Indicate that 145 (47.1\%) of the studied mothers denied their children eating egg as part of their taboo practice.

Table (5): shows that more than half $(55.8 \%)$, less than half $(46.4 \%, \& 43.8 \%)$ of the studied mothers reported positive attitude as they mentioned; gradual weaning is better for the child, baby should be given breast milk only up to 4months, and complementary feeding after 6 months is good for the child respectively while more than one third $(36.7 \%)$ of the studied mothers reported negative attitude as they stated; child should be separated from the mother during complete weaning.

Table (6): Sows that there was a statistically significant association between sociocultural factors and mothers' subjective weaning practice.

Table (1) Socio demographic and economic characteristics of the studied mothers $(n=308)$

\begin{tabular}{|c|c|c|}
\hline 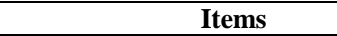 & No. & $\%$ \\
\hline \multicolumn{3}{|l|}{ Age ( in years) } \\
\hline $18-<27$ & 275 & 89.3 \\
\hline $27-\geq 35$ & 33 & 10.7 \\
\hline Mean \pm SD & $18.98 \pm 1.96$ & \\
\hline \multicolumn{3}{|l|}{ Language } \\
\hline Hausa & 200 & 64.9 \\
\hline Fulani & 51 & 16.6 \\
\hline Kanuri and Igbo & 33 & 7.8 \\
\hline Yoruba & 24 & 10.7 \\
\hline \multicolumn{3}{|l|}{ Level of education } \\
\hline Cannot read and write & 40 & 12.9 \\
\hline Primary & 89 & 28.9 \\
\hline Secondary /Technical & 154 & 50.0 \\
\hline University & 25 & 8.2 \\
\hline \multicolumn{3}{|l|}{ Occupation } \\
\hline House wife/unemployed & 192 & 62.3 \\
\hline Civil servant & 62 & 20.2 \\
\hline Skilled worker & 30 & 9.7 \\
\hline Clerk, professional and trade & 24 & 7.8 \\
\hline \multicolumn{3}{|l|}{ Income/month } \\
\hline$<10000 \mathrm{~N}$ & 138 & 44.8 \\
\hline $10000 \mathrm{~N}-<20000 \mathrm{~N}$ & 120 & 38.9 \\
\hline$>20000 \mathrm{~N}$ & 50 & 16.3 \\
\hline \multicolumn{3}{|l|}{ Type of family } \\
\hline Extended & 248 & 80.5 \\
\hline Nuclear & 60 & 19.5 \\
\hline \multicolumn{3}{|l|}{ Number of family members } \\
\hline$<5$ & 50 & 16.2 \\
\hline $5-10$ & 150 & 48.7 \\
\hline $11-\geq 15$ & 180 & 35.1 \\
\hline \multicolumn{3}{|l|}{ Number of children } \\
\hline $1-5$ & 80 & 25.9 \\
\hline $6-10$ & 180 & 58.6 \\
\hline $11-\geq 15$ & 48 & 15.5 \\
\hline
\end{tabular}

N= Naira 
Table (2) Distribution of studied mothers regarding their knowledge score level about weaning $(\mathrm{n}=308)$

\begin{tabular}{|l|c|c|c|c|c|c|}
\hline \multicolumn{1}{|c|}{ Items } & \multicolumn{2}{c|}{ Poor } & \multicolumn{2}{c|}{ Fair } & \multicolumn{3}{c|}{ Good } \\
\hline & No. & $\mathbf{\%}$ & No. & \% & No. & \% \\
\hline Meaning of weaning & 21 & 6.8 & 71 & 23.0 & 261 & 84.7 \\
\hline Principles of weaning & 208 & 67.5 & 75 & 24.3 & 25 & 8.1 \\
\hline Importance of weaning & 80 & 25.9 & 20 & 6.5 & 208 & 67.5 \\
\hline Types of weaning food & 40 & 12.9 & 80 & 25.9 & 188 & 61.0 \\
\hline Proper age of starting weaning & 190 & 61.7 & 8 & 2.6 & 110 & 35.7 \\
\hline Preferred season of weaning & 299 & 97.0 & 4 & 1.3 & 5 & 1.6 \\
\hline Time of starting weaning based on child health & 58 & 18.8 & 5 & 1.6 & 245 & 79.5 \\
\hline Amount of food & 250 & 81.1 & 40 & 12.9 & 18 & 5.8 \\
\hline Number of meals/day & 260 & 84.4 & 35 & & 13 & \\
\hline Weaning schedule & 265 & 86.0 & 20 & 6.5 & 23 & 7.5 \\
\hline Administration of food & 255 & 82.8 & 35 & 11.4 & 18 & 5.8 \\
\hline Method of cooking food & 281 & 91.2 & 15 & 4.9 & 12 & 3.9 \\
\hline Food allergy & 289 & 93.8 & 11 & 3.6 & 8 & 2.6 \\
\hline Total Score & $\mathbf{1 9 2}$ & $\mathbf{6 2 . 3}$ & $\mathbf{2 9}$ & $\mathbf{9 . 5}$ & $\mathbf{8 7}$ & $\mathbf{2 8 . 2}$ \\
\hline Mean + SD & & & $\mathbf{2 4 . 1 8} \pm \mathbf{6 . 3 1}$ & \\
\hline
\end{tabular}

Poor $<50 \%$ of the total score $(<20.5)$

Fair $=50 \%-70 \%$ of total score $(\mathbf{2 0 . 5}-\mathbf{3 0 . 7 5})$

Good $>75 \%$ of the total score $(>30.75)$

Table (3) Distribution of studied mothers regarding their category of subjective weaning practice $(n=308)$

\begin{tabular}{|l|c|c|c|c|}
\hline \multirow{2}{*}{ Items } & \multicolumn{2}{|c|}{ Proper practice } & \multicolumn{2}{c|}{ Improper practice } \\
\cline { 2 - 5 } & No. & $\mathbf{\%}$ & No. & \% \\
\hline Selection criteria & 48 & 15.6 & 260 & 84.4 \\
\hline Food hygiene & 75 & 24.3 & 233 & 75.7 \\
\hline Food Preparation & 76 & 24.7 & 232 & 75.3 \\
\hline Meals preparation & 38 & 12.3 & 270 & 87.7 \\
\hline Cooking of food & 77 & 25.0 & 231 & 75.0 \\
\hline Serving of food & 99 & 32.1 & 209 & 67.9 \\
\hline Food administration & 43 & 14.0 & 265 & $\mathbf{7 8 . 9}$ \\
\hline Total score & $\mathbf{6 5}$ & $\mathbf{2 1 . 1}$ & $\mathbf{2 4 3}$ & \\
\hline Mean \pm SD & \multicolumn{3}{|c|}{$\mathbf{1 4 . 6 1} \pm \mathbf{2 . 1 2}$} \\
\hline
\end{tabular}

Proper practice $>75 \%$ of total score $(>\mathbf{2 7 . 7 5})$

Improper practice $<75 \%$ of the total score $(<27.75)$

Table (4) Distribution of the studied mothers regarding their sociocultural factors affecting weaning practice $(n=308)$

\begin{tabular}{|c|c|c|}
\hline Items & No. & $\%$ \\
\hline \multicolumn{3}{|l|}{ Socio cultural factors } \\
\hline Panting of breast & 80 & 25.9 \\
\hline Use of rubutu & 50 & 16.2 \\
\hline Du'a by malam & 120 & 38.9 \\
\hline Use of herbal preparation & 30 & 9.7 \\
\hline Avoidance of protein food & 10 & 3.2 \\
\hline Taking of raw egg. & 18 & 5.8 \\
\hline \multicolumn{3}{|l|}{ Native weaning food } \\
\hline Tuwo & 50 & 16.2 \\
\hline Kanzo & 10 & 3.2 \\
\hline Rice and beans & 80 & 25.9 \\
\hline Gruel & 60 & 19.5 \\
\hline Pap & 128 & 41.5 \\
\hline \multicolumn{3}{|l|}{ Native weaning practice } \\
\hline Child separation & 150 & 48.7 \\
\hline Putting of dusa on the breast & 80 & 25.9 \\
\hline Early weaning & 20 & 6.5 \\
\hline Use of guru and laya & 58 & 18.8 \\
\hline \multicolumn{3}{|l|}{ Taboos in weaning practice } \\
\hline Egg is prohibited for the child & 145 & 47.1 \\
\hline meat is prohibited for the child & 54 & 17.5 \\
\hline it is very dangerous to withhold water from the infant because the child will grow as a dull & 52 & 16.9 \\
\hline
\end{tabular}




\begin{tabular}{|l|c|c|}
\hline Herbal preparation is given as food and as medicine to ward off evil spirit & 41 & 13.3 \\
\hline Introduction of water before six months promote child intelligence & 14 & 4.5 \\
\hline infant formula can cause diarrhea & 2 & .6 \\
\hline Prohibited food & & \\
\hline Oily food & 30 & 9.7 \\
\hline Egg & 50 & 16.2 \\
\hline Meat & 40 & 12.9 \\
\hline Kanzo & 50 & 16.2 \\
\hline Tuwo & 30 & 9.7 \\
\hline Millet & 10 & 3.2 \\
\hline Fruits and vegetables & 80 & 25.9 \\
\hline Fish & 18 & 5.8 \\
\hline Prohibited practice & & \\
\hline Separation & 40 & 12.9 \\
\hline Use of infant formula & 180 & 58.4 \\
\hline Given raw egg & 80 & 25.9 \\
\hline Weaning of first baby by the mother & 8 & 2.5 \\
\hline
\end{tabular}

Table (5) Distribution of the studied mothers regarding their attitude about weaning $(n=308)$

\begin{tabular}{|c|c|c|c|c|c|c|c|c|}
\hline \multirow[t]{2}{*}{ Attitude categories } & \multicolumn{2}{|c|}{ Strongly agree } & \multicolumn{2}{|c|}{ Agree } & \multicolumn{2}{|c|}{ Disagree } & \multicolumn{2}{|c|}{ Strongly disagree } \\
\hline & No. & $\%$ & No. & $\%$ & No. & $\%$ & No. & $\%$ \\
\hline \multicolumn{9}{|l|}{ Positive attitude } \\
\hline $\begin{array}{l}\text { Gradual weaning is better for the child } \\
(4 \mathrm{mks})\end{array}$ & 40 & 13.0 & 172 & 55.8 & 19 & 6.2 & 77 & 25.0 \\
\hline \multicolumn{9}{|l|}{ Mean \pm SD $\quad 2.00 \pm 1.27$} \\
\hline $\begin{array}{l}\text { Baby should be given breast milk only } \\
\text { up to } 4 \text { months ( } 4 \mathrm{mks})\end{array}$ & 43 & 14.0 & 143 & 46.4 & 43 & 14.0 & 79 & 25.6 \\
\hline Mean \pm SD $\quad 2.18 \pm 1.26$ & & & & & & & & \\
\hline $\begin{array}{l}\text { Baby should be given breast milk only } \\
\text { up to } 6 \text { month ( } 4 \mathrm{mks})\end{array}$ & 55 & 17.9 & 91 & 29.5 & 69 & 22.4 & 93 & 30.2 \\
\hline \multicolumn{9}{|l|}{ Mean \pm SD $\quad 2.53 \pm 1.20$} \\
\hline $\begin{array}{l}\text { Breast feeding should be continued } \\
\text { during weaning }(4 \mathrm{mks})\end{array}$ & 58 & 18.8 & 96 & 31.2 & 55 & 17.9 & 99 & 32.1 \\
\hline \multicolumn{9}{|l|}{$\begin{array}{ll}\text { Mean } \pm \text { SD } & 2.50 \pm 1.23 \\
\end{array}$} \\
\hline $\begin{array}{lcc}\begin{array}{l}\text { Complementary feeding before } \\
\text { months is good for the child }(4 \mathrm{mks})\end{array} & 6 \\
\end{array}$ & 58 & 18.8 & 93 & 30.2 & 62 & 20.1 & 95 & 30.8 \\
\hline \multicolumn{9}{|l|}{ Mean \pm SD $\quad 2.51 \pm 1.21$} \\
\hline $\begin{array}{l}\text { Complementary feeding after } 6 \text { month } \\
\text { is good for the child }(4 \mathrm{mks})\end{array}$ & 109 & 35.4 & 135 & 43.8 & 35 & 11.4 & 29 & 9.4 \\
\hline Mean \pm SD & & & & & & & & \\
\hline \multicolumn{9}{|l|}{ Negative attitude } \\
\hline $\begin{array}{l}\text { Abrupt weaning is better for the child } \\
(4 \mathrm{mks})\end{array}$ & 57 & 18.5 & 46 & 14.9 & 42 & 13.6 & 162 & 52.6 \\
\hline \multicolumn{9}{|l|}{$\begin{array}{ll}\text { Mean } \pm \text { SD } & 3.04 \pm 1.14 \\
\end{array}$} \\
\hline $\begin{array}{l}\text { Early weaning is better for the child } \\
(4 \mathrm{mks})\end{array}$ & 45 & 14.6 & 51 & 16.6 & 52 & 16.9 & 160 & 51.9 \\
\hline \multicolumn{9}{|l|}{ Mean \pm SD $\quad 3.04 \pm 1.15$} \\
\hline $\begin{array}{l}\text { Late weaning is better for the child } \\
(4 \mathrm{mks})\end{array}$ & 54 & 17.5 & 176 & 57.1 & 29 & 9.4 & 49 & 15.9 \\
\hline \multicolumn{9}{|l|}{$\begin{array}{ll}\text { Mean } \pm \text { SD } & 1.84 \pm 1.13 \\
\end{array}$} \\
\hline $\begin{array}{l}\text { Child should be separated from the } \\
\text { mother during complete weaning ( } 4 \mathrm{mks} \\
\text { ) }\end{array}$ & 113 & 36.7 & 132 & 42.9 & 23 & 7.5 & 40 & 13.0 \\
\hline Mean \pm SD & & & & & & & & \\
\hline Total attitude (40) & & & $\mathrm{a} \pm \mathrm{SD}$ & $2.15 \pm$ & & & & \\
\hline
\end{tabular}

Table (6) Association between the studied mothers' sociocultural factors affecting weaning practice and their total score of subjective weaning practice $(n=308)$

\begin{tabular}{|c|c|c|c|c|c|c|}
\hline Items & \multicolumn{4}{|c|}{ Total weaning practice } & \multirow{3}{*}{$\mathbf{X} 2$} & \multirow{3}{*}{$\mathbf{P}$} \\
\hline & \multicolumn{2}{|c|}{ Improper practice } & \multicolumn{2}{|c|}{ Proper practice } & & \\
\hline Socio cultural factors & No. & $\%$ & No. & $\%$ & & \\
\hline Painting of breast & 80 & 26 & 0 & 0 & \multirow{6}{*}{418.348} & \multirow{6}{*}{0.001} \\
\hline Use of rubutu & 80 & 26 & 0 & 0 & & \\
\hline Du'a by malam & 100 & 32.5 & 0 & 0 & & \\
\hline Use of herbal remedy & 20 & 6.5 & 0 & 0 & & \\
\hline Avoidance of protein & 3 & 0.9 & 17 & 5.6 & & \\
\hline Taking of raw egg & 0 & 0 & 8 & 2.6 & & \\
\hline
\end{tabular}


Assessment of Socio-Cultural Factors Affecting Nigerian Mothers' Weaning Practice

\begin{tabular}{|c|c|c|c|c|c|c|}
\hline Native weaning food & & & & & \multirow{6}{*}{165.159} & \multirow{6}{*}{0.000} \\
\hline Tuwo & 50 & 16.2 & 0 & 0 & & \\
\hline Kanzo & 10 & 3.2 & 0 & 0 & & \\
\hline Rice and beans & 80 & 26 & 0 & 0 & & \\
\hline Gruel & 60 & 19.4 & 0 & 0 & & \\
\hline Pap & 83 & 27 & 25 & 8.1 & & \\
\hline \multicolumn{5}{|l|}{ Native weaning practice } & \multirow{5}{*}{256.418} & \multirow{5}{*}{0.004} \\
\hline Child separation & 150 & 49 & 0 & 0 & & \\
\hline Putting of dusa on the breast & 80 & 26 & 0 & 0 & & \\
\hline Early weaning & 20 & 6.5 & 0 & 0 & & \\
\hline Use of guru and laya & 33 & 10.7 & 25 & 8.1 & & \\
\hline \multicolumn{5}{|l|}{ Taboos in weaning practice } & \multirow{7}{*}{400.369} & \multirow{7}{*}{0.000} \\
\hline Egg is prohibited for the child & 145 & 47.0 & 0 & 0 & & \\
\hline Meat is prohibited for the child & 54 & 17.5 & 0 & 0 & & \\
\hline It is dangerous not to give water & 52 & 16.8 & 0 & 0 & & \\
\hline Herbal preparation is given & 32 & 10.3 & 11 & 3.6 & & \\
\hline Given of water promote intelligence & 0 & 0 & 12 & 3.9 & & \\
\hline Infant formula can cause diarrhea & 0 & 0 & 2 & 0.6 & & \\
\hline \multicolumn{5}{|l|}{ Prohibited food } & \multirow{9}{*}{353.424} & \multirow{9}{*}{0.2} \\
\hline Oily food & 30 & 9.7 & 0 & 0 & & \\
\hline Egg & 50 & 16.2 & 0 & 0 & & \\
\hline Meat & 40 & 12.9 & 0 & 0 & & \\
\hline Kanzo & 50 & 16.2 & 0 & 0 & & \\
\hline Tuwo & 30 & 9.7 & 0 & 0 & & \\
\hline Millet & 10 & 3.2 & 0 & 0 & & \\
\hline Fruits and vegetables & 73 & 23.7 & 7 & 2.2 & & \\
\hline Fish & 0 & 0 & 18 & 6 & & \\
\hline \multicolumn{5}{|l|}{ Prohibited practice } & \multirow{5}{*}{179.876} & \multirow{5}{*}{0.000} \\
\hline Seperation & 41 & 13.3 & 0 & 0 & & \\
\hline Use of infant formula & 178 & 57.8 & 0 & 0 & & \\
\hline Given raw egg & 64 & 20.7 & 16 & 5.1 & & \\
\hline Weaning of first baby by mother & 0 & 0 & 9 & 2.9 & & \\
\hline
\end{tabular}

\section{X2=Chi square test}

Statistically significant at $\quad \mathbf{P}<0.05$

\section{Discussion}

Weaning is often beneficial because it reduces early infant mortality. Although the time of weaning differs from society to societies, but always determined by the characteristics, choice, knowledge and perceptions of the mother about the child's health or related to cultural beliefs and diet. Mothers adopt general child health obligations, and mothers' knowledge may be an obstacle to weaning practices (7). However, during weaning practice the mother prechewed the food for the child and this gives the baby long-term immunological benefits through factors in the mother's saliva (8). Proper weaning practice transforms the baby into a time of dietary independence from breastfeeding and confirms appropriate growth and development of the child. Proper weaning practice takes into consideration dietary need, right timing, adequate food consistency, frequency and hygiene. In addition, if weaning practice is not properly done, failure to succeed can be a complication which can lead to infant mortality and morbidity (9).

The present study results revealed that less than one third of the studied mothers had good knowledge score level related to weaning practice. The current finding was disagreeing with (10) who found that less than one third of studied mothers had poor knowledge of complementary feeding. This probably due to fact that majority of the studied mothers were living in a rural area. Less than one fifth of studied mothers had proper category of subjective weaning practice. The present study was in line with (11), who found that, most of studied mothers had improper weaning practices. The reason for improper practice was probably due strong adherence to some traditional practice.

In relation to sociocultural factors, less than half of the studied mothers stated that egg is prohibited for the child during weaning. The current study was in the same vein with (12), who reported that, most of the studied mothers denied eating egg to their children, as well it was in line with (13) who revealed that most of the studied mothers do not give egg to their children. The belief is that it leads children to theft when grow older.

Regarding mothers attitude towards weaning, more than half, and less than half of the studied mothers reported positive attitude as they mentioned; gradual weaning is better for the child, and baby should be given breast milk only up to 4months, and complementary feeding after 6 months is good for the child respectively. The present finding was in agreement with (14), who reported that, more than one third of the studied mothers gradually weaned their children; less than half of them commenced complementary feeding after 6 months of delivery. However, more than one third of the studied mothers reported negative attitude towards child separation during weaning. This finding was in line with (14), who reported that less than one fifth of the 
studied mothers send their children away from home during weaning while majority of them remained with their mothers during the weaning process.

However, from the researcher point of view studied mothers positive attitude toward weaning were due to health talk given to the mothers at maternal and child health center, while their negative attitude was probably due to strict adherence to their cultural tradition.

Concerning association between mothers' sociocultural factors and subjective weaning practice, the present study indicates that, there was statistically significant association between socio cultural factors and mothers' subjective weaning practice. This study was in agreement with (15), who reported that weaning practice among studied mothers was heavily influenced by cultural beliefs and tradition.

\section{Conclusion}

\section{Conclusion \& Recommendations}

In conclusion, mothers' knowledge regarding weaning was poor and subjective practices were improper. Majority of them were not aware of the current recommendations of weaning practice. Additionally, there was a statistically significant association between sociocultural factors and mothers' subjective weaning practice.

\section{Recommendations}

The following recommendations were made based on the findings and conclusion drawn from the study.

- There is need for health care system interventions, family interventions, and public health educations campaigns to promote optimal weaning practices, especially in woman within the reproductive age group.

- It is recommended to develop successful infant-feeding interventions aimed at promoting overall health of the infant,

- It is recommended that; health education program should be reactivated to enlighten mothers on the effect of socio cultural factors on breastfeeding and weaning practice.

\section{References}

[1]. UNICEF/WHO/World Bank (2012). Levels and trends in childhood malnutrition. UNICEF-WHO-World Bank Joint child malnutrition estimates. Geneva. United Nations Children's Fund/World Health Organization/World Bank.

[2]. WHO (2015) Infant and young child feeding [Internet]. WHO. [cited 2015 Jun 15]. Available from: http://www.who.int/mediacentre/factsheets/fs342/en/

[3]. Ram HC. (2015) Knowledge and Practices of Mothers of Infants and young Children on Complementary Feeding. Available From www.researchgate.net/232237378. Accessed march 8, 2017.

[4]. UNICEF( 2012) Infant and young child feeding, nutrition section program. New York. UNICEF. PubMed | Google Scholar

[5]. National Population Commission (NPC) Nigeria, ICF Macro (2009) Nigeria Demographic and Health Survey 2008. National Population Commission and ICF Macro, Abuja

[6]. Federal Ministry of Health (FMH), (2011) saving new-born lives in Nigeria: newborn health in the context of maternal, new-born and child health strategy, 2nd edn. Federal Ministry of Health, Save the Children, Abuja.

[7]. Dandekar, R.H., M. Shafee and R. Kumar (2014) Breastfeeding and weaning practices among literate mothers: a community based study in rural area of Perambalurtaluk, Tamil Nadu. The Health Agenda2 (1):15-21.

[8]. Pelto, Greta; Zhang, Yuanyuan; Habicht, Jean-Pierre (2010), "Premastication: the second arm of infant and young child feeding for health and survival?", Journal of Maternal and Child Nutrition (Blackwell Publishing Ltd), doi:10.1111/j.1740-8709.2009.00200.x, PMID 20073131

[9]. Ram HC. (2015) Knowledge and Practices of Mothers of Infants and young Children on Complementary Feeding. Available From www.researchgate.net/232237378. Accessed march 8, 2017.

[10]. Mohite RV, Mohite VR, Kakade SV (2012). Knowledge of breastfeeding among primigravida mothers. Bangladesh Journal of Medical Sciences; 11(4): 312 -316.

[11]. Swati Kambli (2012) Impact Factor International Journal of Science and Research (IJSR) ISSN (Online): 2319-7064 3.358 Volume 3 Issue 7, July 2014 www.ijsr.netLicensed Under Creative Commons Attribution CC BY Mother's Knowledge Regarding Weaning Process in Infants

[12]. Ekwochi et al (2016) Food taboos and myths in South Eastern Nigeria: The belief and practice of mothers in the region Journal of Ethnobiology and Ethno medicine 12:7 DOI 10.1186/s13002-016-0079-x

[13]. Maduforo AN. ( 2010 ) Superstitions and nutrition among pregnant women in Nwangele Local Government Area of Imo state, Nigeria. Journal of Research in national development; 8(2):1-15

[14]. Aliyu I, Duru C, Lawal TO, Mohammed A, (2014) Breastfeeding and weaning practices among Nigerian women. J Med Investig Pract;9:140-3.

[15]. Schwartz, H, L. (2008). "Infantfeedingpractices and beliefs among women in Podor, WestAfrica"Master'sTheses.Paper 3629. http://scholarworks. sjsu. edu/etd_theses/3629 